\title{
Nurse's Knowledge and Performance Regarding Children with Traumatic Brain Injury at Assiut University Hospital.
}

\author{
Sabah Fawzy Farg, Mohamed Mohamed Abd-Ellatief, Fathia Zaky Mohamed \& Amal Ahmed Mobarak. \\ Head Nurse in Trauma Intensive care Unit at Assiut University Hospital, Egypt. \\ Professor of Anesthesia and intensive care, Faculty of Medicine, Assiut University, Egypt. \\ Assistant Professor of Pediatric Nursing, Faculty of Nursing, Assiut University, Egypt. \\ Lecturer of Pediatric Nursing, Faculty of Nursing, Assiut University, Egypt.
}

\begin{abstract}
Traumatic brain injury (TBI) is no degenerative, congenital insult to the brain from an external mechanical force, possibly leading to permanent or temporary impairment of cognitive, physical and psychosocial functions. Aims assess nurse's knowledge and performance related to the care of children with traumatic brain injury at Assiut University Hospital. A descriptive research design used to conduct this study. The convenience sample involved 71 nurses at Assiut University Hospital (6) working at Cardiopulmonary resuscitations unit, (49) in trauma intensive care unit and (16) trauma intermittent care unit. Results significant differences found between nurse's knowledge and their level of education and between nurse's perform, knowledge and attending training courses $(\mathrm{P}=0.001)$. Conclusion the studied nurses had adequate knowledge and performance about traumatic brain injury statistically significant differences were found between nurses. Recommendations were implemented or prepare rehabilitation program for child family to help them to involve in care of child, develop booklet for nurses about management of pediatric traumatic brain injury in Arabic, encourage comities to develop prevention programs for community for prevent child falling. Establishing a small nursing library in hospital units supplied with Arabic recent books nursing periodicals and procedure manuals.
\end{abstract}

Key words: Trauma, Brain Injury, Nursing \& Children.

\section{Introduction}

Traumatic brain injury (TBI) is no degenerative, congenital insult to the brain from an external mechanical force, possibly leading to permanent or temporary impairment of cognitive, physical, and psychosocial functions, with an associated diminished or altered state of consciousness (Thompson et al., 2011).

Pediatric traumatic brain injury (PTBI) is a major public health problem in the United States (Anderson \& Yeates, 2010). It is the leading cause of neurobehavioral morbidity and permanent disability from trauma in children. The PTBI result in 7400 deaths, 60,000 hospitalizations, 60,000 emergency department visits annually in the United States and is the most common reason that a child will sustain a significant life- long disability (Stanley et al., 2012). Unfortunately, the education of most mental health professionals (including school psychologists) regarding neurobehavioral secuelae of Traumatic brain injury (TBI) is vastly insufficient (Silver et al., 2011).

Brain injury can be divided into two componentsprimary and secondary injury. Primary injury is the mechanical injury caused by the traumatic event itself. Although serious, advances in automotive technology, emergency medical response, and intensive care unit monitoring have helped in ontrolling brain damage caused during this phase of injury. More difficult to control, however the development of secondary brain injury after trauma. This is a result of edema and ischemic changes at the cellular and molecular levels and is a significant challenge in TBI patients (Jagannathan et al., 2007). The common causes of head trauma in children are fall, sports-related injuries, being hit on the head, by an object or by colliding with an obstacle injuries involving the use of a bicycle and injuries involving motor vehicles, especially as a pedestrian. Intracranial injury is more frequent following falls from a height above three feet $(91 \mathrm{~cm}$, or twice the length/height of the individual), involvement in a motor vehicle accident (either as a passenger or a pedestrian) or impact from a high-velocity projectile (Faul et al., 2010).

Children with head trauma may present with a variety of symptoms, including. Headache, amnesia, impaired level of consciousness, disorientation or confusion, vomiting, loss of consciousness, blurred vision and Seizures. Younger children may present with lethargy or irritability. It is difficult to conclude from published studies which, if any, single clinical symptom or sign is a reliable predictor of intracranial injury (Michael, 2016-a). 
Diagnosis of traumatic brain injury include history of traumatic event, neurologic examination which include examination for scalp lesions, skull fractures and cerebro spinal fluid (CSF), pupil size and reactivity, motor and sensory examination that include peripheral and central reflex examination and Glasgow Coma Scale, radiographic studies that include computed tomography (CT) scan of the head and vascular studies including CT angiography and magnetic resonance (MR) angiography (Bullock \& Polishock, 2007).

Several complications can occur immediately or after a traumatic brain injury. Moderate to severe traumatic brain injury can result in prolonged or permanent changes in a person's state of consciousness, awareness or responsiveness. Different states of consciousness include coma, vegetative state, minimally conscious state, locked-in syndrome and Brain death, (Hemphill, 2014). Secondary complication may include cerebral edema, elevated intra cranial pressure (ICP), seizures, electrolyte disturbances, hydrocephalus, dysphasia, hearing loss, vision impairment, extremity weakness, joint/muscle contractures, scoliosis, speech impairment, cognitive impairment, paroxysmal autonomic instability, (Anderson et al., 2009). Posttraumatic sequel may develop in some children with various complications. About 5 percent children may have posttraumatic epilepsy (Percival, 2017).

Prognosis in case of head injury depends upon type of injury, initiation of management and available facilities for specialized care. Most children with head injury recover within 24 to 48 hours. Approximate 70-75 percent of injured children will die, if the initial glasco coma scale (GCS) score is 3 to 4 and about 20 percent may be severely disabled (Percival, 2017).

Management include continuous monitoring of vital signs and, if possible, end-tidal $\mathrm{CO}_{2}$, mechanical ventilation to maintain normal oxygenation and ventilation, maintenance of a normal core temperature, providing sedation and analgesia, particularly during procedures and transport and Fluid administration as required to maintain normovolemia and avoid hypotension (Michael, 2016-b).

The nurse has an important role in caring for children with traumatic brain injury (TBI). Assess and maintain the airway with the jaw-thrust maneuver or through insertion of an oral airway while maintaining cervical spine immobilization and stabilization, administer $100 \%$ oxygen by bag-valvemask ventilation, obtain venous access and initiate an intravenous infusion, measure the child's level of consciousness and neurologic responses, perform on going assessments of the child's cardiopulmonary oxygen saturation and neurologic statuses, insert an or gastric tube to prevent gastric distension, insert an indwelling bladder catheter to measure urinary output, prepare for diagnostic testing such as CT scanning without contrast, prepare for operative management, inform the family frequently about the child's condition and results of diagnostic tests, provide emotional support to the child and family and Initiate consultations with social services, neurosurgery and other specialists, as needed (Parul, 2009).

\section{Significance of the study}

Children with brain trauma are in need for special nursing care to minimize brain complications and improving nursing care given for these children.

Traumatic brain injury (TBI) is a leading cause of death and long-term disability, and results in an enormous economic cost to society, more than 1 . million head injuries occur each year, accounting for 250,000 hospitalizations, 60,000 deaths, and 80,000 patients left with permanent neurologic disability (Aarabi et al., 2001). About 1, 6 million head injuries occur every year, 250,000 require hospitalization and 60,000 deaths are caused by head injuries occur every year. Found that, pediatric head trauma remains the common cause of serious injury and death in children. Seventy-five percent of children who are hospitalized secondary to head trauma. The overall incidence is 200-300 cases per 100,000 in the population annually. Deaths from severe TBI occur at an alarming rate of 7,000 annually. Many childhood survivors of severe TBI are left with varying degrees of permanent disability (American Academy of Pediatrics, 2012).

In Egypt, about 881, cases of traumatic brain injury in children was estimated from hospital records, from them 830 case improved and 51 case died, Assiut University Hospital records, 2010.

\section{Aim of the study}

The aim of the present study is to assess the nurse's knowledge and performance related to the care of children with traumatic brain injury at Assiut University Hospital.

\section{Research question}

- Highly educated nurses' has better knowledge \& performance of patient nursing care than those graduated from technical schools or institute of nursing.

- Nurse who has several years of experience are better in performance than the new graduated nurses.

- Nurses who have experienced many training courses are better in knowledge and performance than the new graduated nurses. 


\section{Subjects and Method \\ Research design}

Descriptive research design was used to conduct this study.

\section{Setting}

The study was conducted in the trauma intermittent care, CPR (Cardiopulmonary Resuscitation) and trauma intensive care units at Assiut University Hospital.

\section{Subjects}

The study includes a convenience sample of (71 nurses') from different units at Assiut University Hospital (6) working in CPR unit, 49 in trauma intensive care unit and in 16 trauma intermittent care unit.

Tools:

Two tools were used to collect the required data for this study.

Tool (1): A structured Questionnaire sheet was developed to collect data for this study and it consists of two parts:-

Part 1. Personal characteristics of the studied nurses' as the nurses' name, age, marital status, years of experiences, their place of work and educational level.

Part 2. Questions to assess nurses' knowledge related to care of children with brain injury as the definition, causes, manifestation, complication, incidence diagnosis, treatment, prognosis and source of information.

II. Tool (2): Observation checklists to assess nurses' performance related to nursing care for children with brain injury (hand washing, gloving, masking, vital signs, IV fluid therapy, insertion of IV cannula, injection, collection of blood specimens, insertion of nesogastric tube, bed bath, mouth care, eye care, change of position, suctioning, oxygen therapy and chest physiotherapy.

\section{Method of data collection}

- An official permission was obtained from the chairmen of each study setting previously method to carry out the study. Confidentiality of the data was asserted. Every nurse was reassured that information obtained be confidential and used only for the purpose of the study.

- The study tools were developed by the researcher and the validity was tested for tools (I \& II) by exposing to five experts in the pediatric field.

A pilot study was carried out on $10 \%$ of the nurses to test the clarity \& applicability of the research tools and to study estimate time needed to fulfill each.

Data was collected by the researcher through interviewing the nurses in groups ( 3 nurses) to deliver the developed questionnaire sheet to them to collect the needed data. The time needed to fulfill each sheet for each interview ranged from 20-30 minutes to fill sheet depending upon the response of the participant nurses. Data were collected during the period from the beginning of May 2012 to October 2012.

4-Indirect observation was done for every nurse in the two shift (morning and afternoon) by the researcher during and after her actual nursing performance to the children with brain injury using the developed observational checklists (tool II). The average time taken for observing every nurse (from 3-5 nurses) ranged from 1-1.5 hours for four procedures daily.

\section{Scoring system}

A structure questionnaire sheet.

The score that was given for subject's responses was two for correctly done, one for done incompletely and zero for incorrect and the total scoring of nurse's knowledge was done as follows: Poor $=$ less than 50\%, Satisfactory $=50 \%$ to less than $70 \%$ and Good $=$ $70 \%$ and more.

Observation checklists sheet.

The score that was given for subjects responses was two for completely done, one for done in completely and zero for not done and the total scoring for nurse' performance was done as follows: In adequate $=$ less than $70 \%$, and adequate $=70 \%$ and more.

\section{Statistical analysis of the data}

The statistical analysis was done using SPSS-12 statistical software package and. Data were presented using descriptive statistics in the form of frequencies and percentages for qualitative variables and standard deviations for quantities variable. Quantitative continuous data were compared by using student $t-$ test. Qualitative variables were compared using chisquare test. Statistical significance was considered at p-value $<0.05$. 


\section{Results}

Table (1): Personal characteristics of the studied nurses' $(n=71)$.

\begin{tabular}{|c|c|c|}
\hline & No. $(n=71)$ & $\%$ \\
\hline $\begin{array}{c}\text { Age in years } \\
20-<30 \\
30 \text { or more }\end{array}$ & $\begin{array}{c}63 \\
8\end{array}$ & $\begin{array}{l}88.7 \\
11.3\end{array}$ \\
\hline Mean \pm SD & \multicolumn{2}{|c|}{$29.81 \pm 7.55$} \\
\hline $\begin{array}{l}\text { Residence } \\
\text { Urban } \\
\text { Rural }\end{array}$ & $\begin{array}{l}37 \\
34\end{array}$ & $\begin{array}{l}52.1 \\
47.9\end{array}$ \\
\hline $\begin{array}{l}\text { Level of education } \\
\text { Diploma of Nursing school } \\
\text { Technical Institute Nursing } \\
\text { Bachelor of Nursing Science }\end{array}$ & $\begin{array}{l}37 \\
15 \\
19\end{array}$ & $\begin{array}{l}52.1 \\
21.1 \\
26.8\end{array}$ \\
\hline $\begin{array}{l}\text { Years of experience } \\
\quad<5 \\
5-<10 \\
10 \text { or more }\end{array}$ & $\begin{array}{l}18 \\
41 \\
12\end{array}$ & $\begin{array}{l}25.4 \\
57.7 \\
16.9\end{array}$ \\
\hline Mean \pm SD & \multicolumn{2}{|c|}{$10.32 \pm 6.84$} \\
\hline $\begin{array}{l}\text { Marital status } \\
\text { Married } \\
\text { Single }\end{array}$ & $\begin{array}{l}41 \\
30\end{array}$ & $\begin{array}{l}57.7 \\
42.3\end{array}$ \\
\hline $\begin{array}{l}\text { Attending training courses } \\
\text { Yes } \\
\text { No }\end{array}$ & $\begin{array}{l}11 \\
60\end{array}$ & $\begin{array}{l}15.5 \\
84.5\end{array}$ \\
\hline
\end{tabular}

Table (2): Percentages distribution of the studied nurse's knowledge regarding traumatic brain injury in children $(\mathbf{n}=71)$.

\begin{tabular}{|l|c|c|c|c|c|c|}
\hline \multirow{2}{*}{ Items } & \multicolumn{2}{c|}{$\begin{array}{c}\text { Complete } \\
\text { correct }\end{array}$} & \multicolumn{2}{c|}{ Incomplete correct } & \multicolumn{2}{|c|}{ Incorrect } \\
\cline { 2 - 7 } & $\mathbf{N o .}$ & $\mathbf{\%}$ & No. & \% & No. & $\%$ \\
\hline 1-Definition of traumatic brain injury & 22 & 31.0 & 40 & 56.3 & 9 & 12.7 \\
\hline 2-Causes of traumatic brain injury & 16 & 22.5 & 55 & 77.5 & 0 & 0.0 \\
\hline 3-Signs and symptoms of traumatic brain injury & 9 & 12.7 & 62 & 87.3 & 0 & 0.0 \\
\hline 4-Diagnosis of traumatic brain injury & 52 & 73.2 & 19 & 26.8 & 0 & 0.0 \\
\hline 5-Treatment of traumatic brain injury & 54 & 76.1 & 17 & 23.9 & 0 & 0.0 \\
\hline 6-Prognosis & 34 & 47.9 & 37 & 52.1 & 0 & 0.0 \\
\hline 7-Prevention of traumatic brain injury & 49 & 69.0 & 19 & 26.8 & 3 & 4.2 \\
\hline
\end{tabular}

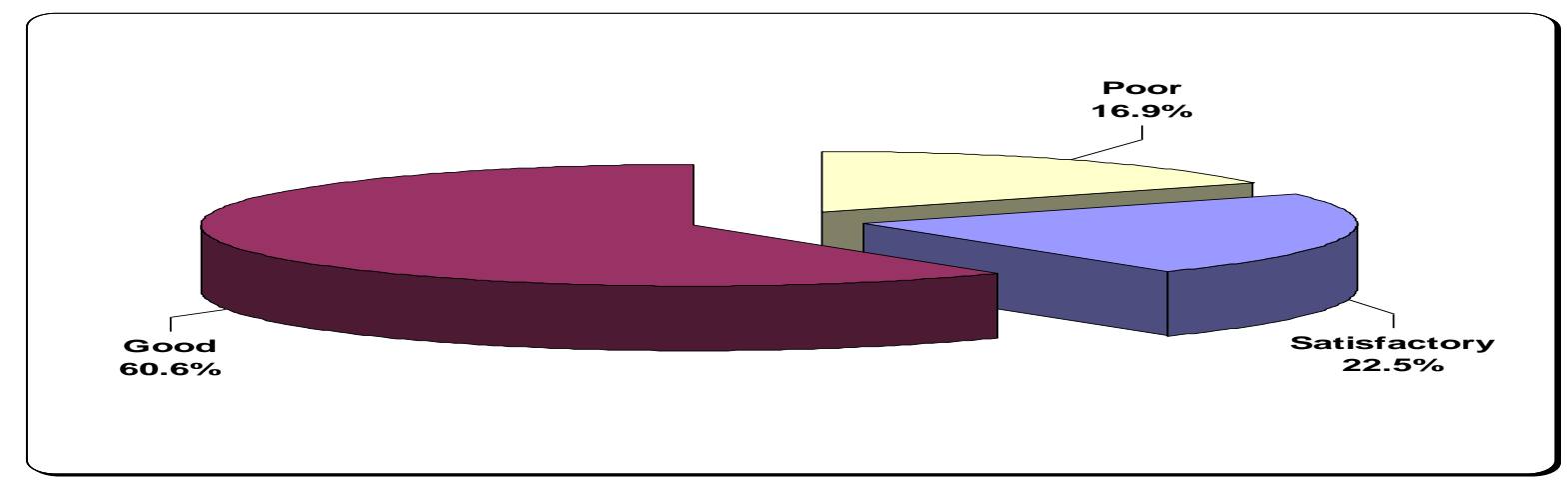

Figure (1): Total means score of the studied nurse's level of knowledge regarding traumatic brain injury in children $(n=71)$. 
Table (3): Total means score of the studied nurse's level of performance regarding traumatic brain injury in children $(n=71)$.

\begin{tabular}{|c|c|c|}
\hline Total percent score of practices & No. $(\mathbf{n}=\mathbf{7 1})$ & \% \\
\hline Inadequate $(<70 \%)$ & 19 & 26.8 \\
\hline Adequate $(\geq 70 \%)$ & 52 & 73.2 \\
\hline
\end{tabular}

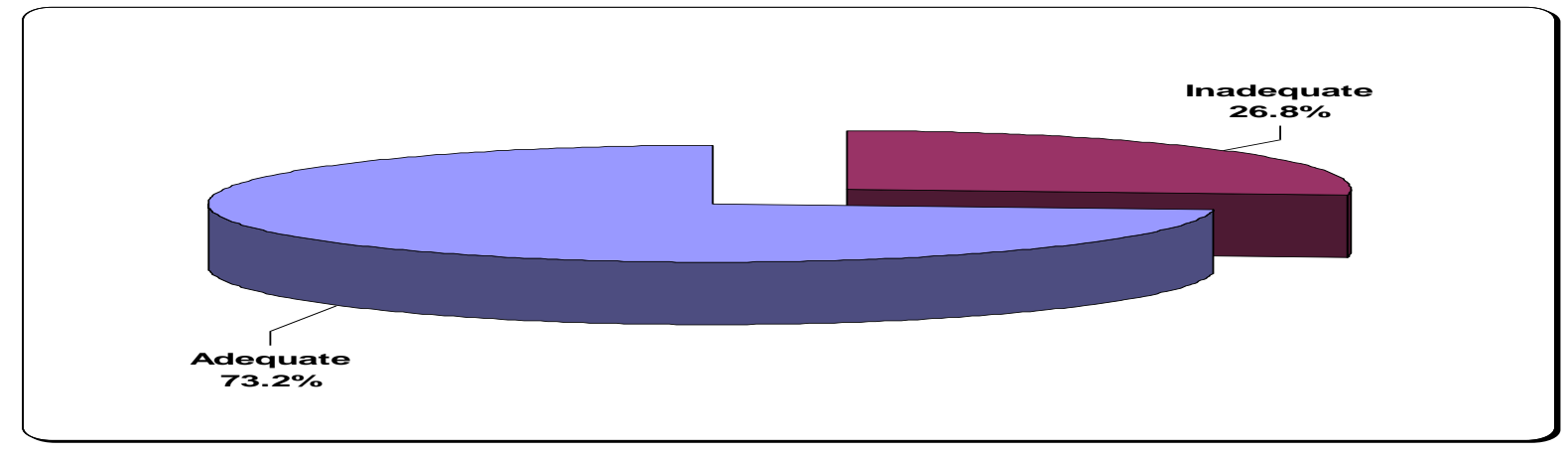

Figure (2): Total means score of the studied nurse's level of practices regarding traumatic brain injury in children $(n=71)$.

Table (4): Relation between score of the studied nurse's practice and their personal characteristics.

\begin{tabular}{|c|c|c|c|c|c|}
\hline \multirow{3}{*}{ Personal characteristics } & \multicolumn{4}{|c|}{ Nurses' practices } & \multirow{3}{*}{ P-value } \\
\hline & \multicolumn{2}{|c|}{$\begin{array}{c}\text { Inadequate } \\
(n=19)\end{array}$} & \multicolumn{2}{|c|}{$\begin{array}{c}\text { Adequate } \\
(n=52)\end{array}$} & \\
\hline & No. & $\%$ & No. & $\%$ & \\
\hline $\begin{array}{c}\text { Age in years } \\
20-<30 \\
30-<40\end{array}$ & $\begin{array}{c}18 \\
1\end{array}$ & $\begin{array}{l}28.6 \\
12.5\end{array}$ & $\begin{array}{c}45 \\
7\end{array}$ & $\begin{array}{l}71.4 \\
87.5 \\
\end{array}$ & 0.333 \\
\hline $\begin{array}{l}\text { Residence: } \\
\text { Urban } \\
\text { Rural }\end{array}$ & $\begin{array}{c}13 \\
6\end{array}$ & $\begin{array}{l}35.1 \\
17.6\end{array}$ & $\begin{array}{l}24 \\
28\end{array}$ & $\begin{array}{l}64.9 \\
82.4\end{array}$ & 0.096 \\
\hline $\begin{array}{l}\text { Level of education: } \\
\text { Diploma } \\
\text { Technical Institute Nursing } \\
\text { Bachelor of Nursing Science } \\
\end{array}$ & $\begin{array}{l}13 \\
5 \\
1\end{array}$ & $\begin{array}{c}35.1 \\
33.3 \\
5.3 \\
\end{array}$ & $\begin{array}{l}24 \\
10 \\
18 \\
\end{array}$ & $\begin{array}{l}64.9 \\
66.7 \\
94.7\end{array}$ & $0.047 *$ \\
\hline $\begin{array}{l}\text { Years of experience: } \\
\quad<5 \\
5-<10 \\
10-<20\end{array}$ & $\begin{array}{c}3 \\
12 \\
4\end{array}$ & $\begin{array}{l}16.7 \\
29.3 \\
33.3\end{array}$ & $\begin{array}{c}15 \\
29 \\
8\end{array}$ & $\begin{array}{l}83.3 \\
70.7 \\
66.7\end{array}$ & 0.514 \\
\hline $\begin{array}{l}\text { Marital status: } \\
\text { Married } \\
\text { Single } \\
\end{array}$ & $\begin{array}{c}13 \\
6 \\
\end{array}$ & $\begin{array}{l}31.7 \\
20.0\end{array}$ & $\begin{array}{l}28 \\
24 \\
\end{array}$ & $\begin{array}{l}68.3 \\
80.0 \\
\end{array}$ & 0.271 \\
\hline $\begin{array}{l}\text { Attending training courses: } \\
\text { Yes } \\
\text { No }\end{array}$ & $\begin{array}{c}0 \\
19\end{array}$ & $\begin{array}{c}0 \\
31.7\end{array}$ & $\begin{array}{l}11 \\
41\end{array}$ & $\begin{array}{c}100.0 \\
68.3\end{array}$ & $0.029 *$ \\
\hline
\end{tabular}




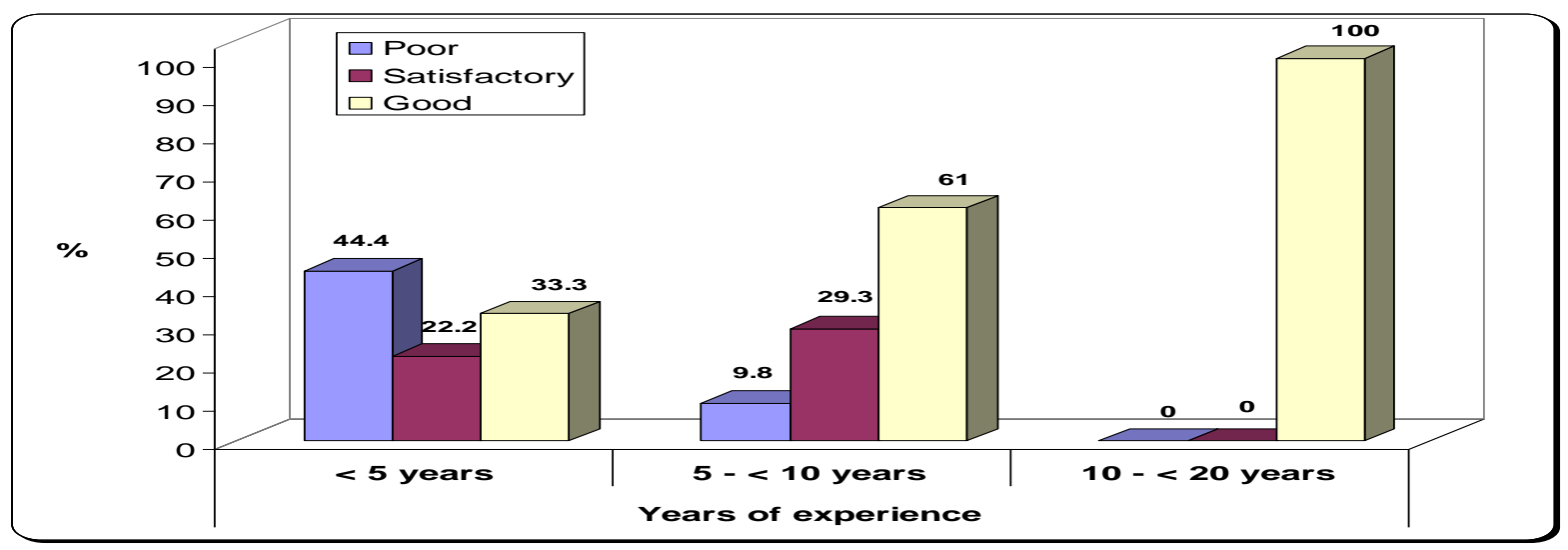

Figure (3): The relation between level of total nurses' knowledge regarding traumatic brain injury in children and their years of experience.

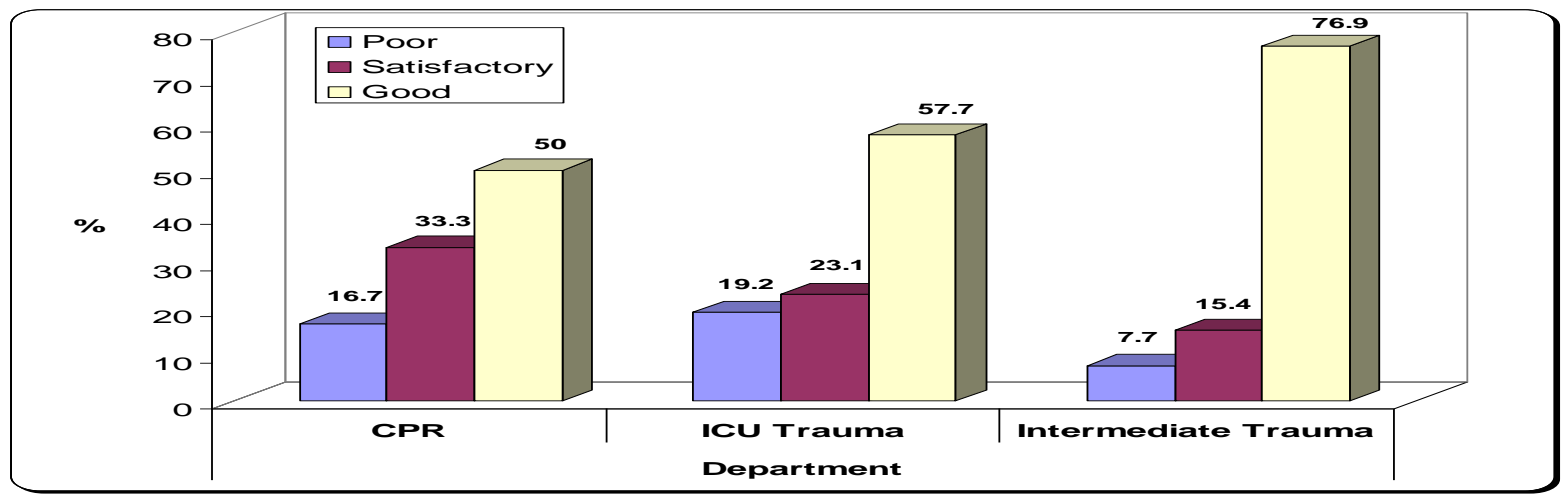

Figure (4): The relation between level of nurses' knowledge regarding traumatic brain injury in children and their attending training courses by department.

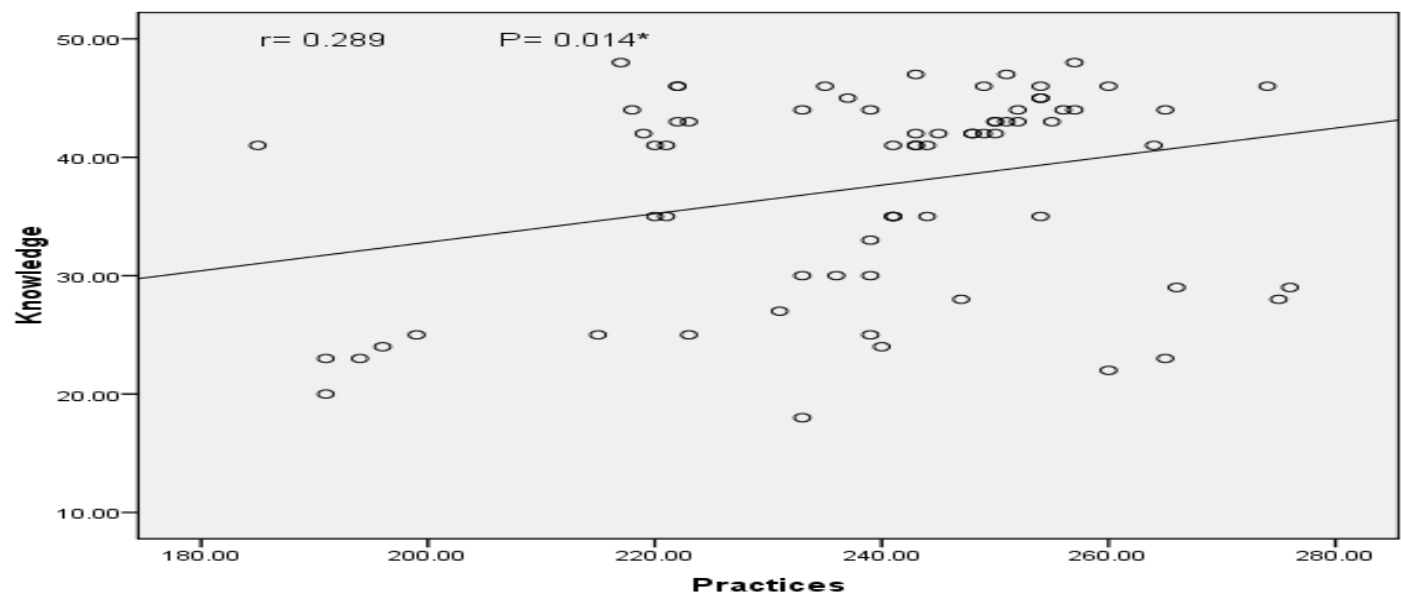

Figure (5): Correlation between total means scores of the studied nurse's knowledge and practices. 
Table (1): Shows the personal characteristics of the studied nurse's. It was found that most of the studied nurse's $88,7 \%$ age ranged from $20-<30$ years and only $11.3 \%$ of them had 30 years or more with the mean age \pm SD was $29.81 \pm 7.55$. More than half of studied nurses were coming from the urban areas and the rest $47.9 \%$ of them were coming from the rural areas. More than half of $52.1 \%$ the studied $52.1 \%$ nurse's had diploma of nursing, technical institute nursing $21.1 \%$ and $26.8 \%$ of them had bachelor of nursing science. Regarding years of experiences, $57.7 \%$ of nurse's had $5<10$ years, mean \pm SD was $10.32 \pm$ 6.48.More than half of nurses were married $57.7 \%$, it was found that $84.5 \%$ of nurses didn't attend training courses. Regarding department. It was found that three quarter of them $73.2 \%$ working in ICU Trauma while, $18.3 \%$ of them working in Intermediate Trauma and $8.5 \%$ of nurse's working in CPR department.

Table (2): Indicates Percentages distribution of the studied nurse's knowledge regarding traumatic brain injury in children $(n=71)$. It was noticed that more than half $56.3 \%$ of the studied nurse's know definition of traumatic brain injury incomplete correct. Regarding causes of traumatic brain injury more than three-quarter $76.1 \%$ of them know causes of traumatic brain injury complete correct. It was noticed that the majority of studied nurse's $87.3 \%$ know Signs and symptoms of traumatic brain injury incomplete correct. According to diagnosis of children with traumatic brain injury $73.2 \%$ of the studied nurse's know diagnosis of children with traumatic brain injury complete correct According to treatment of children with traumatic brain injury more than three-quarter $76.1 \%$ of the studied nurse's know treatment of children with traumatic brain injury complete correct. Regarding to complications of traumatic brain injury whole of the studied nurses $100.0 \%$ know complications of traumatic brain injury incomplete correct. Prognoses of traumatic brain injury more than half $52.1 \%$ of them know incomplete correct. Regarding prevention of traumatic brain injury more than three-fifth $69.0 \%$ of the studied nurse's know prevention of traumatic brain injury complete correct.

Figure (1): Shows that the total means a score of the studied nurse's level of knowledge regarding traumatic brain injury in children $(n=71)$. It was noticed that about $60.6 \%$ of the studied nurse's had good score. While $22.5 \%$ of them had a satisfactory score and $16.9 \%$ of them were poor.

Table (3): Indicates the total means score of the studied nurse's level of performance regarding traumatic brain injury in children $(n=71)$. It was noticed that three-quarter of studied nurse's $73.2 \%$ had adequate score while $26.8 \%$ of them had inadequate score.

Figure (2): Shows that indicates the total means score of the studied nurse's knowledge regarding traumatic brain injury in children $(n=71)$. It was noticed that more than three-quarter of the studied nurse's $73.2 \%$ had adequate score while $26.8 \%$ of them had inadequate score.

Table (4): Presents relation between score of the studied nurse's practice and personal their characteristics. There is no statistical significance difference between age and level of practice and there is no statistical significance difference between residence and level of practice. Also there is statistical significance difference between level of education and level of practice with P.value (0.047). There is no statistical significance difference between years of experience and there is no statistical significance difference between marital status and level of practice. There is statistical significance difference between attending training courses and level of practice with P.value (0.029). There is no statistical significance difference between department and level of practice.

Figure (3): Shows that the relation between level of total nurses' knowledge regarding traumatic brain injury in children and their years of experience. There is statistical significance difference between Years of experience and level of knowledge with P-value $(0.000)$.

Figure (4): Shows that the relation between level of nurses' knowledge is regarding traumatic brain injury in children and their attending training courses by department. There is not statistical significance difference between Department and level of knowledge.

Figure (5): Show that the Correlation between total means scores of the studied nurse's knowledge and practices. There is positive correlation between level of studied nurse's knowledge and their practices. When increased level of knowledge increased level of practices.

\section{Discussion}

Traumatic brain injury (TBI) is one of the leading causes of mortality in the pediatric population. Furthermore, even pediatric patients who are to survive from (TBI) may be left with severe neurocognitive and physical disabilities (Giza \& Pins, 2006). The pediatric nurse's has an important role in caring for children with traumatic brain injury to prevent secondary brain injury through maintenance of a patient air way, fluid and electrolyte balance, adequate nutritional status, maintenance of normal body temperature, maintenance of skin integrity, effective family coping health education about 
rehabilitation process and prevention of complications. Initially neurologic and systematic assessments are made at frequent intervals throughout the acute phase of pediatric patients care (Smeltzer \& Bare, 2004).

Results of the present study revealed that the majority of the studied nurse's were in the age group from 2030 years old, married and most of them have Diploma of Secondary Nursing School, current job experience from $5<10$ years. These results were in an agreement with Hassan, (2010) \& Gadalla, (1998) found that the majority of the nurse's ages ranged from $20-<30$ years, married and have Diploma of Secondary Nursing School the majority of the nurse's ages ranged from 20 - to $<30$ years and married.

As regard years of experience, it was noticed that more than half of the studied nurse's had experience from $5<10$ years. These results agree with Hassan, (2010) who stated that the majority of nurse's had experience range from $5<10$ years. While disagrees with Gadalla, (1998) who found that the majority of nurse's had experience range from $1<5$ years.

The present study showed that studied nurse's, with experience $<5$ years had adequate practice $83.3 \%$. These results are in agree with Gamal, (2005) who found that the youngest nurse's, with <1-year experience had more knowledge and better practice of universal precautions than older nurses with more experience. On the opposite side, Abolwafa, (2009) reported that Total scores of nurse's knowledge and performance having work experience ranged from $5<10$ years were higher than those who having worked experience $<5$ years. Mohamed, (2010) stated that the nurse who had $<5$ years of experience had satisfactory score in her performance.

The present study indicated that about $56.3 \%$ of nurse's had in complete correct answer related to definition causes and prognosis of traumatic brain edema about more than one-quarter of nurse's related to causes, majority of them related to signs \& symptoms and all of them related to complications while more than one-quarter of nurses had correct answer related to diagnosis and treatment. This could be related to hospital politics or system which does not offer nurse's any opportunity for pre, in- service or special courses on important subjects that are related to their work and this will enhance an improvement and be updating their knowledge. In addition, nurse's might be poor in related to lacking updating knowledge, Available suitable educational materials, and refresher courses. They did not attend any organization program to improve their knowledge about traumatic brain injury as well as lack of educational preparation for the majority of them. These results are in line with those obtained by Ghallab (1994) who reported that nurse's knowledge fell far short of the level required and was less than the anticipated level.

The present study showed that $61.7 \%$ who were in early twenties $<25$ years had better total percent score of performance these result agree Mohamed, (2010).

The findings of this study illustrated that majority of studied nurses didn't wash their hands. This result may be attributed to the multi-procedures implemented for the care of the dependent critically. Patient's in the ICUS, the absence of sink in patient's area and the lack of supplies namely soap, paper towel and alcohol, and skin irritation that frequent hand washing, insufficient time to accomplish that task. This agree with Pratte, (2001) who stated that hand contamination is one of the main contributing factors in the current infection threat; contaminated hands are responsible for transmitting infection rates in high-risk areas and also with Kanal, (2004) who observed that $33.3 \%$ of nurse's had poor practice between hand washing procedure. Intramuscular injections should be given into the densest part of the muscle tissue under the subcutaneous tissue. The vascularity of muscle aids the rapid absorption of medication (Dougherty \& Lister, 2011).

The present study showed that $100.0 \%$ of nurse's had done correct cleans the skin with an alcohol sponge. This agree with Sachidananda Kamath, (2006) who clarified that cleaning the site of injection is a good clinical practice. It decreases number of microorganisms present in the skin and may reduce the risk of abscess. If alcohol is used for cleaning, it should be allowed to dry before injection is given and the majority of studied nurse's $100 \%$ clean the skin with an alcohol sponge, insert the needle at 90 degree angle and $69 \%$ of them record date, time, name of the medication, dose, route, site, any given complaint or observation and signature these results are agree with Burden, (1994) and Department of Health, (2012). On the other hand, these findings are disagree with Khawaja, (2010) who mentioned that $98.0 \%$ of nurse's not using a swab of alcohol or skin preparation will increased the risk of infection; therefore they should not receive an injection without alcohol swab. This result may attributed to lack of supplies namely; alcohol, paper towel and alcohol sponge.

Oral care is the most important and the most effective measure in preventing reduction of the salivary volume dryness of the mouth, formation of dental plague, gingival and dental infections (Johnstone \& Koziol-McClain 2010) The results of the present study that $100 \%$ of the studied nurse's give oral care to children with traumatic brain injury this may be related to the availability of resources in the unit. 
It was found in the present study that there is no statistical significant difference between age of studied nurse's and their level of practice. This might be due to older nurse had many years of experience may require a minimum of additional instruction before they are ready to take a patient assignment, nurse's with years of experiences in one clinical specialty may need a moderate amount of instruction to through training program and should not consider the age, position, and professional qualification as a barrier for learning new things in the field of nursing.

This agree with said, (2004) who found that higher rates of nurse's who had satisfactory level of performance existed among the older age of nurse's this disagree with Ali, (2011) who stated that the young aged nurse's, who is more active, initiative has good physical fitness and creative in achieving the nursing performance. On the same line Mohamed, (2010) who stated that more than two-thirds of nurse's $61.7 \%$ who were in early twenties $<25$ years had better score of performance.

The results in the present study showed that there is no statistical significant difference between studied nurse's knowledge scores, and practice with their age and this agree with Hassan, (2010) who stated that there was no statistical significant difference between nurse's knowledge scores and practice with age.

The current study showed that $83.3 \%$ of nurse's who had $<5$ years of experience had higher rate of performance than other nurse's. This observation may be explained by nurse's who have more experience will be responsible for administrative and managerial activities, while younger ones have more practical work in direct patient care. This agree with Gamal, (2005) who found the youngest nurse's with $<1$-year experience had better practice than older nurse's with more experience. This is agreeing with Azer, (2005) who reported that new nurse's had a score of performance higher the old nurse's. On the same line Mohamed, (2010) who stated that the nurse who had $<5$ years of experience had satisfactory score in her performance.

This is disagreeing with Gadalla, (1998) who stated that nurse's, with more years of experience had higher rate of performance than other nurses. Also disagree with Hassan, (2010) who stated that no statistical significant difference between the scores of nurse's practice and their experience observed during the pretest and disagree with Ebrahaem, (2009)who also mentioned that unsatisfactory performance scores were found for the majority of nurse's who had $<5$ years of experience.

The results in the present study showed that there is statistical significant difference between nurse's knowledge and their practice. These results disagree with Hassan, (2010) who stated that there is a statistical significant difference between nurse's knowledge and this practice observed during the pretest. This may be attributed to insufficient courses included in their undergraduate curriculum of nursing education and also there is no available Arabic source for updating and continuing their education

\section{Conclusion}

Based on the results of this study, it can be concluded that the studied nurse's had adequate knowledge and practice about traumatic brain injury with statistical significant difference and there is statistical significant difference between nurse's knowledge scores and practice with level of education, attending courses and their years of experience with $\mathrm{P}$-value (0.000).

\section{Recommendations}

Based on the findings of the present study, the following recommendations are suggested

- Implement or prepare rehabilitation program for child family to help them to involve in care of child.

- Develop booklet for nurses about management of pediatric traumatic brain injury in Arabic.

- Encourage the commities to develop the prevention programs for community for prevent child falling and increase awareness of families

- Encouraging the nurse's to improve and update their knowledge by reading. This can be achieved by establishing a small nursing library in hospital units supplied with Arabic recent books nursing periodicals and procedure manuals.

- Nurse's practices have to be continually monitored supervised continuously by nursing audits and supervisors, as well as the infection control committee members and regular staff meeting and conferences must be conducted to discuss work problems and needed resources.

\section{References}

1. Abolwafa, N., (2009): Assessment of nurse's, Knowledge and Performance related to infection control in neonatal units at El-Minia city hospitals. Master thesis Faculty of nursing Assiut University.

2. Ali, M., (2011): Assessment of nurse's, Knowledge and Performance related to universal infection control precautions (UICP) at Mallawy general hospital departments. Master thesis, Faculty of nursing, Assiut University.

3. Anderson, V., Catroppa D., \& Morse S., (2009): Intellectual outcome from preschool traumatic brain injury a 5 year prospective, 
Longitudinal study pediatrics. 2009; 124: $1064-$ 1071.

4. Anderson, V., \& Yeates, K., (2010): Introduction pediatric traumatic brain injury. New frontiers in clinical and translational research frontiers in clinical and translational research. In V. Anderson, \& K. Yeates, (Eds.), Pediatric traumatic brain injury: new frontiers in clinical and translational. Research, (Pp.1-6). New York: Cambridge University Press.

5. Azer, S., (2005): A study of factors affecting nurses' performance Thesis, B.Sc. Nursing, Faculty of nursing, Adult N. department, Assiut. University.

6. Beder, N., \& Michel H., (2004): Impact of universal infection control. Intervention program for nurses'. Alexandria Scientific Nursing Journal; 3(1) Pp.71-82.

7. Burden, M. (1994): A practical guide to insulin injections. Nursing Standard 8, 29, 25-29.

8. Bulloch, M., \& Polishock, J., (2007): Guidelines for the management of severe traumatic brain injury (3 rd edition).J. Neurotrauma, 2007; 24 (Suppl 1): S1-nce-based guidelines from an expert panel.

9. Department of Health, (2012): Immunization against Infectious Disease; the Green Book http:// www. dh. Gov. uk / tag/ green- book/

10. Dougherty, L., \& Lister, S., (2011): The Royal Marsden Manual of Clinical Nursing Procedures - Eighth Edition. Blackwell Publishing, Oxford.

11. Michel, J., Verive, M., FAAP. (2016-a): Pediatric head trauma. American Academy of Pediatrics, Society for Pediatric Sedation.

12. Michel, J., Verive, M., FAAP. (2016-b): Pediatric head trauma treatment Management. American Academy of Pediatrics, Society for Pediatric Sedation.

13. Ebrahem, G., (2009): Nurse's application of infection control precautions in hemodialysis unit at El-mansoura university children's hospital. Unpublished master in pediatric nursing. Faculty of Nursing University of Alexandria.

14. Gadalla, M., (1998): A study of assessment of nurses' performance and knowledge at Assiut hospitals. Thesis, B.Sc. Nursing, Faculty of nursing, Pediatric nursing department, Assiut University.

15. Gamal, L., (2005): Establishing standards for prevention of nosocomial infection in the recovery rooms and surgical ward at El-Minia university hospital. For doctoral degree in critical care nursing, Faculty of Nursing Assiut University.
16. Giza, C., \& Prins, M., (2006): Is being plastic fantastic. Mechanisms of ahered plasticity after developmental traumatic brain injury.Dev.Neuroci.28, 364-379 (2006). Gordon KE. Pediatric minor traumatic brain injury Semin Ped Neurol 2006; 13 (4):243 55.

17. Greenberge, M., (2001): Handbook of Neurosurgery (5 th edn) Thieme, New York: Chapter; 7 p: 51.

18. Ghallab, S., (1994): Developing and implementing an in-service education on aseptic techniques and principles of sterilization for nurses' working in surgical departments of Assiut University Hospital.

19. Percival, H., Pangiliman, J., (2017): Classification and complications of traumatic brain injury. American Academy of Physical Medicine and Rehabilitation, Association of Academic Physiatrists.

20. Hassan, A., (2010): Risk factor of neonatal sepsis in neonatal intensive care unit, Assiut university children Hospital. Unpublished MD, Assiut University.

21. 20) Hemphill, J., (2014): Management of acute severe traumatic brain injury. http://www.uptodate.com/home. Accessed Feb. 7, 2014.

22. Jagannathan, J., Okonkwo, D., \& Dumont, A., (2007): Outcome following decompressive craniectomy in children with severe traumatic brain injury: a 10-year single-center experience long-term follow up.J.Neurosurg, 106,268-275 (2007).

23. Johnstone, L., Spence, D., \& Koziol-McClain, J., (2010): Oral hygiene care in the pediatric intensive care unit: Practice recommendations. Pediatric nurse, 36 (2): 85-96.

24. Kanal, A., (2004): Assessment of health team knowledge and practice about infection control in maternal child health centers in Assiut city. Master thesis, department of community health nursing, Faculty of Nursing, Assiut University.

25. Khawaja, R., (2010): Knowledge, attitude and practices towards routine skin preparation before an injection among physicians, nurses' and patients in a teaching hospital of Saudi Arabia, department of family and community medicine, collage of medicine, King Khalid University Hospital and King Saudi University h://www.mejfm.com/march 2010/injection.htm.

26. Mohamed, F., (2010): Nurse's performance of incubator terminal care in university children hospital in Alexandria. Unpublished master thesis in pediatric nursing. Faculty of Nursing University of Alexandria. 
27. Oyce, M., \& Jane, H., (2009): Medical-Surgical Nursing Clinical Management for Positive.8thed, Lippincott Williams \& Wilkins, Pp.325-335.

28. Parul, D., (2009): Pediatric Nursing. Second Edition p: 410-411.

29. Pratte, R., (2001): The Development of National Evidence-Based Guidelines for Prevention Hospital Acquired Infection in England. London: Thomas vally University. Available at www. Epic ivu. Ac UK.

30. Povlishock, J., \& Katz, D., (2005): Update of Neuropathology and Neurological Recovery after Trauma Rehabilitation 2005; 20 (1); 76-94.

31. Royal College of nursing (2005): Good practice in infection prevention and control Guidance for nursing staff.UK.

32. Said, H., (2004): Knowledge and practices of nurses' regarding hand washing and Use of gloves in patient's wards in Alexandria Hospitals. Unpublished master thesis. High Institute of Public Health University of Alexandria.

33. Sachidananda, Kamath, (2006): National conference of pediatric infectious disease. pediatriconcall.http:www.pediatriconcall com/for doctor abstracts /cupid 2006/artic le7.asp.

34. Silver, J., McAllister, T., \& Yudovsky, S., (2011): Textbook of traumatic brain injury, New York: Guilford Press.

35. Smeltzer, S., \& Bar, B., (2004): Hand washing. Textbook of medical surgical nursing 10 th ed Philadelphia Lippincott Williams and Wilkins company; pp 2124-3125.

36. Stanley, R., Bonsu, B., Zhao, W., Ehrlich, P., Rogers, A., \& Xiang, H., (2012): U.S estimates of hospitalized children with severe traumatic brain injury: Implications for clinical trials. Pediatrics, 129, 24-30.

37. Thompson, D., Hurtado, T.R, Liao, M., Byyny, R., Gravitz, C., \& Haukoos, J., (2011): Validation of the simplified motor score in the out-of-Hospital setting for the prediction of outcomes after traumatic brain injury. Ann Emerge Med. Nov 2011; 58(5):417-25. 